\title{
Changes in Contents of Ginsenoside Due to Boiling Process of Panax ginseng C.A. Mayer
}

\author{
In Je Sung, Amal Kumar Ghimeray, Kwang Jin Chang ${ }^{1}$ and Cheol Ho Park* \\ Department of Bio-Health Technology, Kangwon National University, Chuncheon 200-701, Korea \\ ${ }^{1}$ Department of Medicinal and Industrial Crops, Korea National University of Agriculture and Fisheries, \\ Hwasung 445-760, Korea
}

\begin{abstract}
The purpose of the study was to determine a method to use fresh white Korean ginseng in the form of higher intake of medicinal components. Decoction was made at $70^{\circ} \mathrm{C}$ and $90^{\circ} \mathrm{C}$ in different intervals of time. HPLC (DAD) system was employed to monitor the ginsenosides content in the decoctions and the components were identified by comparing the retention time with that of reference compounds. However, decoction made at $70^{\circ} \mathrm{C}$ in $72 \mathrm{hrs}$ possessed higher amount of total ginsenosides $(209.6 \mathrm{\mu g} / \mathrm{mL})$ content where considerable amount of bioactive ginsenosides like $\mathrm{Rg} 3, \mathrm{Rb} 2, \mathrm{Rb} 1 \mathrm{and} \mathrm{Rg} 1$ were accumulated. Overall, it can be concluded that the fresh white Korean ginseng decoction made in $72 \mathrm{hrs}$ at $70^{\circ} \mathrm{C}$ would be useful for the health and other medicinal approach of ginseng.
\end{abstract}

Key words - Decoction, White Korean ginseng, Ginsenoside

\section{Introduction}

During the last several decades, great progress has been made on the research of the bioactivity, chemistry and clinical efficacy of ginseng (Li et al., 2010). Ginsenoside is the main pharmacological component of Panax ginseng. Among the discovered ginsenosides in white ginseng, $\operatorname{Rg} 1$ (protopanaxatriols) is considered as stimulator of central nervous system and involved in adaptogen activity (Ko et al., 2009). Likewise, Rh2 has anti-allergic (Park et al., 2003) and anticancer activity (Guo et al., 2012). Rg3 and compound $\mathrm{K}$ are generally not present in white ginseng, but after processing by steaming or drying, these compounds can be generated artificially. These compounds are reported to show antitumor (Keum et al., 2003), antioxidant (Keum et al., 2000), and lowering blood pressure (Kim et al., 1999). Rb1 and Rb2 also reported to have antiviral, antidiabetic activity and anti-hyperlipidemic effect (Yoo et al., 2013; Lee et al., 2011).

Decoction is a traditional method for extraction of chemical components (organic compounds, oils etc) by boiling with water from plant materials like roots, barks, stem, fruits etc.

${ }^{*}$ Corresponding author. E-mail : chpark@kangwon.ac.kr
Decoctions can produce liquids with different chemical properties as the temperature, time and preparation varies. In general, people still practice traditional method of consumption of ginseng by boiling with water (decoction). However, there are no clear indications of standardization decoctions of fresh white Korean ginseng which have higher functional ginsenoside content. Standardized decoctions can increase the quality and bioactivity of ginseng. Recently, there was a report of decoctions of white ginseng where the alteration of ginsenosides was observed (Jin et al., 2012). However, their investigation was based on the sulfur-fumigated white ginseng during post harvest handling. Therefore, to the best of our knowledge, no standardization of ginsenoside compound has been reported using fresh white Korean ginseng decoctions. Therefore, the aim of the present study was to develop a decoction method to enhance the functional ginsenosides ( $\mathrm{Rb} 1, \mathrm{Rb} 2, \mathrm{Rg} 1, \mathrm{Rg} 3$, $\mathrm{Rh} 2$, and $\mathrm{C}-\mathrm{K}$ ) in fresh white Korean ginseng.

\section{Materials and Methods}

\section{Chemicals and Standards}

HPLC grade acetonitrile was purchased from Merck (Germany). All other chemicals and solvents were of analytical 
grade. The deionised water was prepared with a Milli-Q water purification system (Millipore, Bedford, MA, USA). The standards reference samples of ginsenosides $\mathrm{Rb} 1, \mathrm{Rb} 2, \mathrm{Rg} 1$, $\mathrm{Rg} 3, \mathrm{Rh} 2$, and C-K were purchased from Sigma-Aldrich. The standard's stock solutions were prepared by dissolving with methanol $(100 \mu \mathrm{g} / \mathrm{mL})$ and were stored at $4{ }^{\circ} \mathrm{C}$ for further analysis.

\section{Collection of ginseng roots and preparation of ginseng decoction extracts}

Fresh six years old Korean ginseng root grown in an organic system using lime Sulfur complex at Gyeongi province, South Korea were harvested in the month of October 2011. The roots were ranged from $37.5 \mathrm{~g}$ to $50 \mathrm{~g}$ in fresh weight. The fresh white Korean ginseng root was accurately weighted (approximately 20 gram each) and refluxed with $200 \mathrm{~mL}$ of water for 24,48 , and $72 \mathrm{hrs}$ at $70^{\circ} \mathrm{C}$ and $90^{\circ} \mathrm{C}$ in a water bath. After cooling, the samples were filtered and used for further experiment.

\section{Ginsenoside analysis by HPLC}

HPLC analysis of ginsenosides in the decoctioned extracts was carried out on Agilent 1260 Infinity Quaternary LC System consist of diode array detector (DAD) and 1260 Evaporative Light Scattering detector (ELSD) with auto injector using Eclipse XDB C18 column $(150 \times 4.6 \mathrm{~mm}, 3.5$ micron Phenomenex. Inc., Torrance, CA, USA). HPLC conditions were as follows: Solvent A (water) and solvent B (acetonitrile) was prepared.

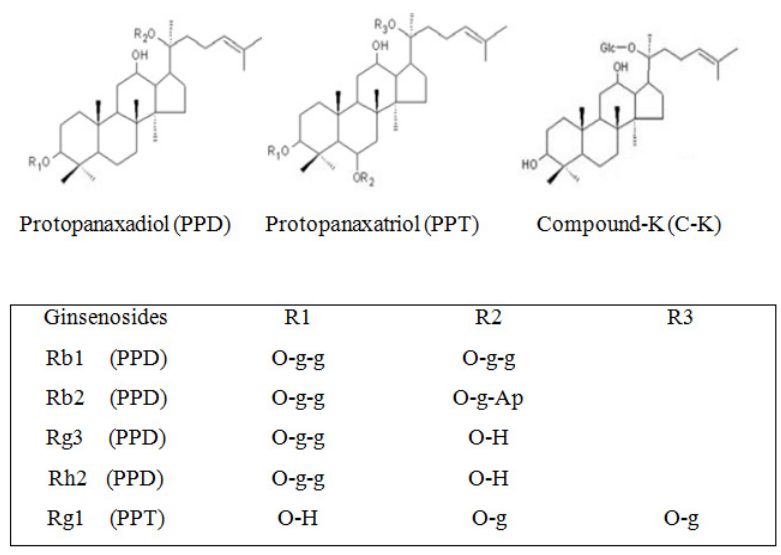

Fig. 1. Chemical structure of ginsenosides (Rb1, Rb2, Rg3, $\mathrm{Rh} 2, \mathrm{Rg} 1$ and $\mathrm{C}-\mathrm{K}$ ) used in the experiment. Abbreviations refer to the following: Ap=arabinopyranose, $g=$ glucopyranose.
Gradient elution was used for 0-30 min, 17-21\% B; 30-35 min, 21-23\% B; 35-45 min, 23-25\% B; 45-65 min, 25-40\% B; $65-85 \mathrm{~min}, 40-65 \% \mathrm{~B}$; 85-95 $\mathrm{min}, 65-75 \% \mathrm{~B}$. The flow rate of mobile phase solution was $1.5 \mathrm{~mL} / \mathrm{min}$, and detection was carried out at $203 \mathrm{~nm} .20 \mu \mathrm{L}$ of each sample was injected. The compounds were identified in solvents by matching their retention times and spectra with that of the standards and the data were calculated on the basis of the peak area obtained.

\section{Statistical analysis}

All data were expressed as the mean value \pm standard deviation (SD) of each experimental group $(n=3)$. The results were processed using Excel 2003 (Microsoft, Redmond, WA, USA).

\section{Results and Discussion}

\section{Ginsenosides content at $70{ }^{\circ} \mathrm{C}$ decoction extracts}

High temperature can change the properties of water thus making the polarity of water closer to those of non-polar compounds. This will enhance the solubility of less polar compounds in water for extraction from different matrices (Toe et al., 2010; Ong et al., 2000). In our research, decoction was made using boiling water which can exude higher amount of photochemical or may cause transformation of glycosideattached ginsenosides (Fig. 1) to another form in temperature and time dependent manner.

Fig. 2 represents the ginsenoside quantification at $70^{\circ} \mathrm{C}$ for $24 \mathrm{hrs}$ treatment. In the given temperature and time, total ginsenoside was calculated as $104.9 \mu \mathrm{g} / \mathrm{mL}$. The individual compounds like $\mathrm{Rb} 1, \mathrm{Rb} 2$ and $\mathrm{Rg} 1$ were also detected and

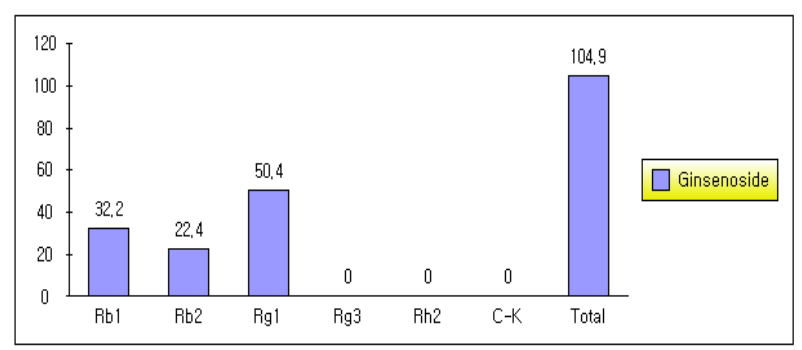

Fig. 2. Ginsenosides (Rb1, Rb2, Rg3, Rh2, Rg1 and C-K) content in the $24 \mathrm{hrs}$ treated decoction at $70^{\circ} \mathrm{C}$. The content is expressed in $\mu \mathrm{g} / \mathrm{mL}$. 


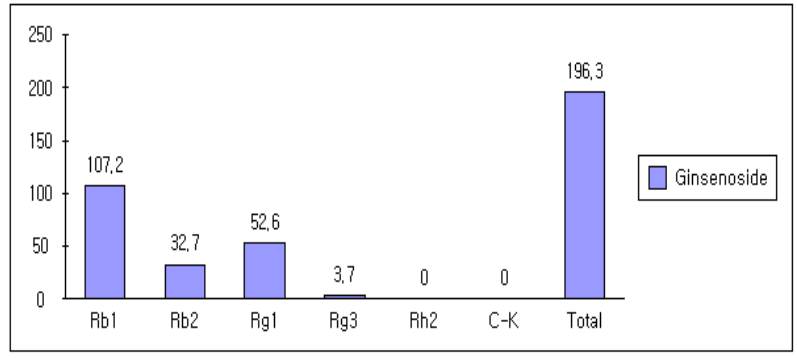

Fig. 3. Ginsenosides (Rb1, Rb2, Rg3, Rh2, Rg1 and C-K) content in the $48 \mathrm{hrs}$ treated decoction at $70^{\circ} \mathrm{C}$. The content is expressed in $\mu \mathrm{g} / \mathrm{mL}$.

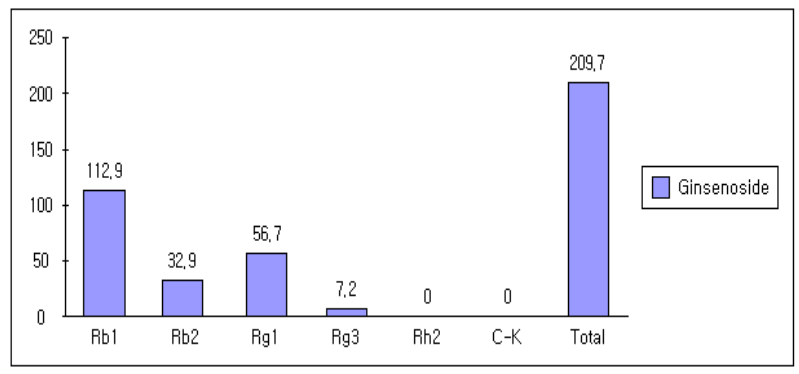

Fig. 4. Ginsenosides (Rb1, Rb2, Rg3, Rh2, Rg1 and C-K) content in the $72 \mathrm{hrs}$ treated decoction at $70^{\circ} \mathrm{C}$. The content is expressed in $\mu \mathrm{g} / \mathrm{mL}$.

found to be 32.2, 22.4 and $50.4 \mu \mathrm{g} / \mathrm{mL}$ respectively; however, other ginsenosides $\mathrm{Rg} 3, \mathrm{Rh} 2$ and $\mathrm{C}-\mathrm{K}$ were not observed. In 48 hrs of treatment at $70^{\circ} \mathrm{C}$ (Fig. 3), the ginsenoside Rb1 increased to $107.2 \mu \mathrm{g} / \mathrm{mL}$ followed by $\mathrm{Rg} 1$ and $\mathrm{Rb} 2$ with $52.6 \mu \mathrm{g} / \mathrm{mL}$ and $32.7 \mu \mathrm{g} / \mathrm{mL}$ respectively. Similarly, the total ginsenoside was also increased to $196.3 \mu \mathrm{g} / \mathrm{mL}$, which was 1.9 times increase than that of $24 \mathrm{hrs}$ treatment. During the treatment $\mathrm{Rg} 3$ ginsenoside was also detected to be $3.7 \mu \mathrm{g} / \mathrm{mL}$. As the time increased for $72 \mathrm{hrs}$ at $70^{\circ} \mathrm{C}$, the $\mathrm{Rb} 1$ concentration was accounted to $112.9 \mu \mathrm{g} / \mathrm{mL}$ followed by $\mathrm{Rg} 1$ and $\mathrm{Rb} 2$ with 56.7 $\mu \mathrm{g} / \mathrm{mL}$ and $32.9 \mu \mathrm{g} / \mathrm{mL}$ respectively (Fig. 4). The Rg3 compound was also increased by 1.9 fold as compare to $48 \mathrm{hrs}$ treatments at the same temperature; however, $\mathrm{Rh} 2$ and $\mathrm{C}-\mathrm{K}$ were not detected. In the given treatment, total ginsenoside was increased to $209.7 \mu \mathrm{g} / \mathrm{mL}$, which was about 2.0 times higher than the treatment at $70^{\circ} \mathrm{C}$ for $24 \mathrm{hrs}$.

\section{Ginsenosides content at $90^{\circ} \mathrm{C}$ decoction extracts}

The ginsenoside present in decoction extracts at $90^{\circ} \mathrm{C}$ for 24 hrs was shown in Fig. 5. The ginsenosides Rb1, Rb2, Rg1 and

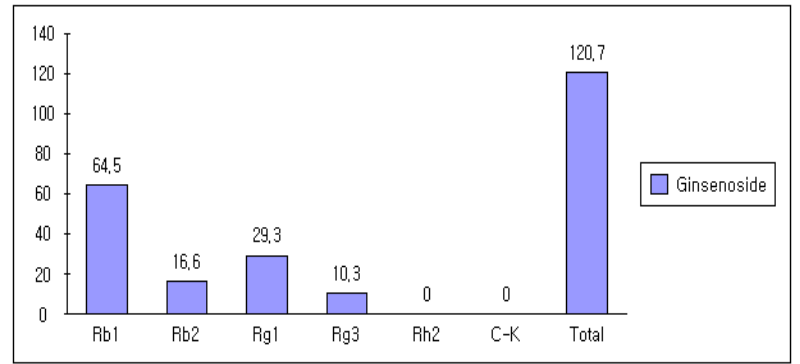

Fig. 5. Ginsenosides (Rb1, Rb2, Rg3, Rh2, Rg1 and C-K) content in the $24 \mathrm{hrs}$ treated decoction at $90^{\circ} \mathrm{C}$. The content is expressed in $\mu \mathrm{g} / \mathrm{mL}$.

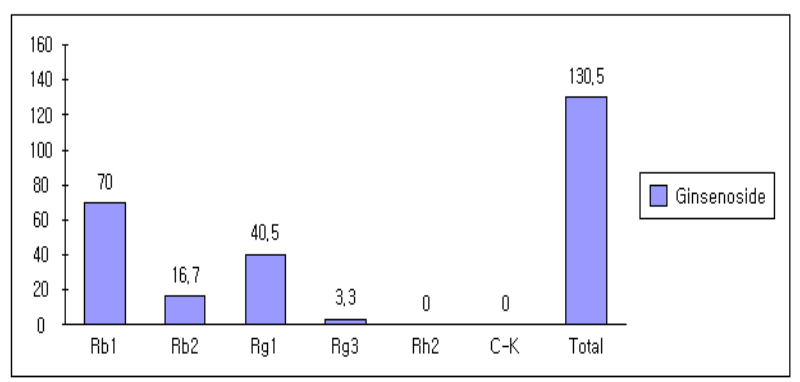

Fig. 6. Ginsenosides (Rb1, Rb2, Rg3, Rh2, Rg1 and C-K) content in the $48 \mathrm{hrs}$ treated decoction at $90^{\circ} \mathrm{C}$. The content is expressed in $\mu \mathrm{g} / \mathrm{mL}$.

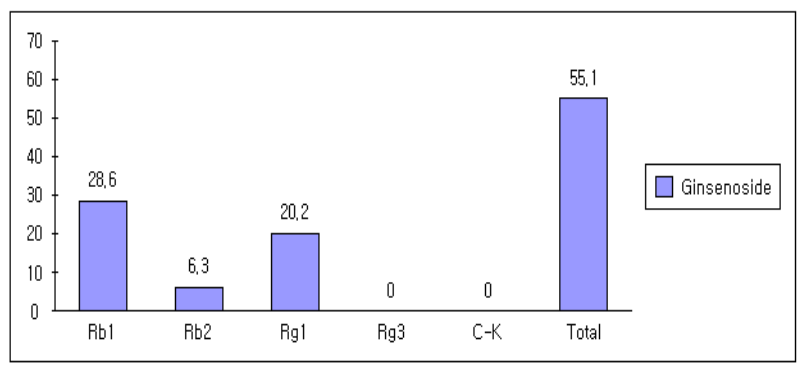

Fig. 7. Ginsenosides (Rb1, Rb2, Rg3, Rh2, Rg1 and C-K) content in the $72 \mathrm{hrs}$ treated decoction at $90^{\circ} \mathrm{C}$. The content is expressed in $\mu \mathrm{g} / \mathrm{mL}$.

$\mathrm{Rg} 3$ content were $64.5,16.6,29.3$ and $10.3 \mu \mathrm{g} / \mathrm{mL}$ respectively at the given time and temperature. Comparing to the data of 24 hrs at $70^{\circ} \mathrm{C}$, there was an increase in total ginsenoside content to $120.7 \mu \mathrm{g} / \mathrm{mL}$. However, Rb2 and $\mathrm{Rg} 1$ were decreased by 1.3 and 1.7 folds respectively. During the treatment, there was a formation of $\mathrm{Rg} 3$ ginsenoside $(10.3 \mu \mathrm{g} / \mathrm{mL})$ which may be formed from the transformation process of other ginsenosides.

The increased amount of $\mathrm{Rb} 1$ ginsenoside with $70 \mu \mathrm{g} / \mathrm{mL}$ was shown in the Fig. 6. Similarly, Rg1 also increased 1.4 fold 
compared to $24 \mathrm{hrs}$ treatment at the same temperature. In contrast, $\operatorname{Rg} 3$ decreased by 3 folds $(3.3 \mu \mathrm{g} / \mathrm{mL})$. The total ginsenoside content was slightly increased to $130.5 \mu \mathrm{g} / \mathrm{mL}$ compared to $24 \mathrm{hrs}$ treatment. When boiling time increased to $72 \mathrm{hrs}$, the content of Rb1, Rb2 and Rg1 ginsenosides decreased and other ginsenosides viz. $\mathrm{Rg} 3, \mathrm{Rh} 2$ and $\mathrm{C}-\mathrm{K}$ were not detected (Fig. 7). Comparing to $48 \mathrm{hrs}$ treatments, the Rb1, Rb2 and $\operatorname{Rg} 1$ decreased by $2.4,2.6$, and 2.0 folds respectively. Similarly, total ginsenoside also reduced to $55.1 \mu \mathrm{g} / \mathrm{mL}$, which was 2.4 fold less than that of $48 \mathrm{hrs}$ treatments at $90^{\circ} \mathrm{C}$.

\section{Conclusion}

Our results highlighted the content of some major ginsenoside compound in fresh white Korean ginseng decoctions in different temperature and time. Among the ginsenoside compounds (Rb1, Rb2, Rg1, Rg3, Rh2 and C-K) used for investigation, $\mathrm{Rh} 2$ and $\mathrm{C}-\mathrm{K}$ were not detected in any of the treatments. Therefore, their availability could be related to the intensity of the reactions such as hydrolysis and oxidation that occur during increased temperatures (Toe et al., 2010). However, Rg3 was detected during the decoction of fresh white Korean ginseng. It has been well known that ginsenosides undergoes transformation by different factors like heat, acid hydrolysis, enzymatic activities (Han et al., 1982; Kim et al., 2007; Cheng et al., 2006; Eom et al., 2009) etc. Therefore, the mechanism involved in the formation for $\mathrm{Rg} 3$ ginsenosides in the treatment could be due to hydrolysis, deglycosylation or addition reactions of the many original ginsenosides in white ginseng (Li et al., 2010). Summarizing the overall data, decoction made at $70^{\circ} \mathrm{C}$ in 72 hrs possessed higher amount of total ginsenosides $(209.7 \mu \mathrm{g} / \mathrm{mL})$ content where considerable amount of bioactive ginsenosides like Rg3, Rb2, Rb1 and Rg1 were accumulated. Therefore, it can be concluded that the fresh white Korean ginseng decoction made in $72 \mathrm{hrs}$ at $70^{\circ} \mathrm{C}$ would be useful for the health and other medicinal approach of ginseng.

\section{Acknowledgement}

Authors appreciate the Institute of Bioscience \& Biotechnology Kangwon National University for supporting research fund.

\section{Literature Cited}

Cheng, L.Q., M.K. Kim, J.W. Lee, Y.J. Lee and D.C. Yang. 2006. Conversion of major ginsenoside $\mathrm{Rb}$ sub (1) to ginsenoside $\mathrm{F}$ sub (2) by Caulobecter leidyia. Biotechnol. Lett. 28:1121-1127.

Eom, H.E., S.H. Seo, A.K. Ghimeray, C.H. Jin, E.Y. Kang, W.S. Kang, I.M. Chung and D.H. Cho. 2008. Changes of protopanaxadiol ginsenosides in ginseng leaves by far infrared and steaming heat treatment. Korean J. Medicinal Crop Sci. 16:332-336.

Guo, X.X., Q. Guo, Y. Li, S.K. Lee, X.N. Wei and Y.H. Jin. 2012. Ginsenoside $\mathrm{Rh} 2$ induces human hepatoma cell apoptosis via Bac/Bak triggered cytochrome $\mathrm{C}$ release and caspase-9/ caspase-8 activation. Int. J. Mol. Sci. 13(12) :15523-15535.

Han, B.H., M.H. Park, Y.N. Han, L.K. Woo, U. Sankawa, S. Yahara and O. Tanaka. 1982. Degradation of ginseng saponins under mild acidic conditions. Plants Med. 44:146-149.

Jin, X., L.Y. Zhu, H. Shen, J. Xu, S.L. Li, X.B. Jia, H. Cai, B.C. Cai and Yan R. 2012. Influence of sulphur-fumigation on the quality of white ginseng: a quantitative evaluation of major ginsenosides by high performance liquid chromatography. Food Chem. 135:1141-1147.

Ko, S.K., O.K. Cho, H.M. Bae, B.W. Yang, B.O. Im, Y.T. Hahm, K.N. Kim, S.H. Cho, J.Y. Kim, S.H. Chung and B.Y. Lee. 2009. Changes in ginsenoside composition of white ginseng by fermentation. Food Sci. Biotechnol. 18: 253-256.

Keum, Y.S, S.S. Han, K.S. Chun, K.K. Park, J.H. Park, S.K. Lee and Y.J. Surh. 2003. Inhibitory effects of the ginsenoside Rg3 on phorbol ester-induced cyclooxygenase- 2 expression, NF- kappa B activation and tumor promotion. Mutat. Res. 523:75-85.

Kim, N.D., S.Y. Kang, J.H. Park and V.B. Schini-Kerth. 1999. Ginsenoside Rg3 mediated endothelium-dependent relaxation in response to ginsenosides in rat aorta: role of $\mathrm{K}+$ channels. Eur. J. Pharmacol. 367:41-49.

Keum, Y.S., K.K. Park, J.M. Lee, K.S. Chun, J.H. Park, S.K. Lee, H. Kwon and Y.J. Surh. 2000. Antioxidant and anti-tumor promoting activities of the methanol extract of heat-processed ginseng. Cancer Lett. 150:41-48.

Kim, K.T., K.M. Yoo, J.W. Lee, S.H. Eom, I.K. Hwang and C.Y. Lee. 2007. Protective effect of steamed American ginseng (Panax guinquefolius L.) on V79-4 cells induced by oxidative stress. J. Ethnopharmacol. 111:443-450.

Lee, K.T., T.W. Jung, H.J. Lee, S.G. Kim, Y.S. Shin and W.K. 
Whang. 2011. The antidiabetic effect of ginsenoside Rb2 via activation of AMPK. Arch. Pharm. Res. 34:1201-1208.

Li, S.L., S.F. Lai, J.Z. Song, C.F. Qiao, X. Liu, Y. Zhou, H. Cai, B.C. Cai and H.X. Xu. 2010. Decocting-induced chemical transformations and global quality of Du-Shen-Tang, the decoction of ginseng evaluated by UPLC-Q-TOF-MS/MS based chemical profiling approach. J. Pharmaceut. Biomed. Anal. 53:946-957.

Ong, E.S., S.O. Woo and Y.L. Yong. 2000. Pressurized liquid extraction of berberine and aristolochic acids in medicinal plants. J. Chromatogr. A. 904:57-64.
Park, E.K., M.K. Choo, E.J. Kim, M.J. Han and D.H. Kim. 2003. Anti-allergic activity of ginsenoside Rh2. Biol. Pharm. Bull. 26:1581-1584

Toe, C.C., S.N. Tan, J.W.H. Yong, C.S. Hew and E.S. Ong. 2010. Pressurized hot water extractions (PHWE). J. Chromatogr. A. 1217:2484-2494.

Yoo, Y.C., J. Lee, S.R. Park, K.Y. Nam, Y.H. Cho and J.E. Choi. 2013. Protective effect of ginsenoside-Rb2 from Korean red ginseng on the lethal infection of haemagglutinating virus of Japan in mice. J. Ginseng Res. 37:80-86.

(Received 7 November 2013 ; Revised 4 December 2013 ; Accepted 9 December 2013) 